\title{
Human umbilical cord-derived mesenchymal stromal cells ameliorated motor defects of 6-OHDA-induced rat model of Parkinson's disease
}

\author{
Fabin Han ${ }^{1,6, *}$, Chao Chen ${ }^{1, *}$, Wei Wang ${ }^{1, *}$, Hao Song ${ }^{1}$, Sen Li $^{1}$, Jing Duan ${ }^{1}$, Xianjie \\ Lu $^{1}$, Shichao Wu ${ }^{1}$, Nan Zhang ${ }^{1}$, Qingfa Chen ${ }^{1}$, Yan Wang ${ }^{1}$, Shuwei Liu ${ }^{2}$, Chongluo \\ Fu $^{3}$, Chengbiao Lu ${ }^{4}$ and Paul Lu ${ }^{5}$ \\ ${ }^{1}$ Centre for Stem Cells and Regenerative Medicine, The Institute for Tissue Engineering \& Regenerative Medicine, Liaocheng \\ University/The Liaocheng People's Hospital, Liaocheng, Shandong, China \\ ${ }^{2}$ Department of Human Anatomy, Shandong University, Jinan, Shandong, China \\ ${ }^{3}$ College of Biological Science, Liaocheng University, Liaocheng, Shandong, China \\ ${ }^{4}$ Department of Neurobiology, Xinxiang Medical College, Xinxiang, Henan, China \\ ${ }^{5}$ Department of Neurosciences, University of California at San Diego, La Jolla, CA, USA \\ ${ }^{6}$ The Institute for Translational Medicine, The Second Affiliated Hospital, Shandong University, Jinan, Shandong, China \\ *These authors have contributed equally to this work \\ Correspondence to: Fabin Han, email: fhan2013@126.com \\ Keywords: Parkinson's disease; dopamine neuronal differentiation; umbilical cord-derived mesenchymal stromal cell; \\ transplantation; gerotarget \\ Received: July 29, $2017 \quad$ Accepted: January 01, $2018 \quad$ Published: January 02, 2018 \\ Copyright: Han et al. This is an open-access article distributed under the terms of the Creative Commons Attribution License 3.0 \\ (CC BY 3.0), which permits unrestricted use, distribution, and reproduction in any medium, provided the original author and source \\ are credited.
}

\section{ABSTRACT}

Cell therapy have a great potential for the treatment of neurodegenerative disease, such as Parkinson's disease (PD). Human umbilical cord-derived mesenchymal stromal cells (hUC-MSCs) have been reported to have multipotent differentiation ability. However, the therapeutic impact and mechanisms of dopamine neuronal differentiation from hUC-MSCs in PD are not determined. Here we developed a new protocol to induce dopamine neuron conversion from hUC-MSCs by addition of the growth cocktail containing noggin, CHIR99021, SHH, FGF8, TGF $\beta$, GDNF, and BDNF. Then we transplanted the hUC-MSCs and the growth factor cocktail into the lesion side of the midbrain of 6-OHDA lesioned rat model of PD. The effects of hUC-MSC transplantation on the dopaminergic neuronal differentiation and motor behaviors of the rats were investigated. We found that in the presence of these molecules, the cultured hUC-MSCs showed a high efficient DA neuronal conversion in vitro. In combination with the growth cocktail, grafted hUC-MSCs also showed a highly efficient DA neuronal conversion in the midbrain of 6-OHDA lesioned rats. Both the grafted hUC-MSCs and the differentiated TH-positive neurons survived in 6-OHDA lesioned rats during the post-grafting period of 16 weeks. The hUC-MSCs-derived TH-positive neurons displayed the same electrophysiological profile as DA neurons in vivo. More importantly, rats with transplanted hUC-MSCs showed progressive improvements in motor behaviors compared to controls from weeks 4 to 16 post-grafting. These results demonstrated the efficacy and usefulness of the growth cocktail in combination with hUC-MSC transplantation in 6-OHDA lesioned rats and provided a promising cell-based treatment strategy for the PD patients. 


\section{INTRODUCTION}

Parkinson's disease (PD) is one of the most prevalent neurodegenerative diseases, affecting $1 \%$ of the population aged 60 years and older and $3-5 \%$ of the population above the age of 85 [1-3]. The motor symptoms of PD are mainly caused by the progressive loss of dopamine (DA) neurons in the substantia nigra (SN), which leads to a disruption of the nigro-striatal neural circuitry and a dopaminergic depletion of the striatum [4, 5]. On the basis of the above pathological mechanism, extant treatments for PD seek to increase DA levels by using carbidopa to reduce DA degradation in the peripheral blood [6], the DA agonist Levo-dopa to increase dopamine production [7] or deep brain stimulation to the nucleus subthalamicus [8] to increase dopaminergic functions.

Although current treatments do improve some symptoms of PD patients, their effects are transient. The long-term therapeutic effects of current treatments on PD are not satisfactory as the consequent side-effects were recognized [9]. Therefore, the search for more efficient and long-term effective treatment methods for PD is still ongoing. Of the new treatment strategies, cell-based therapy represents a promising therapeutic approach to replace the missing DA neurons and restore the motor function of PD patients. Experimental studies on rodent and non-human primate models for PD in the 1970s and 1980s showed that fetal brain-derived DA neurons could survive, re-innervate the striatum and release DA after grafted [10-14]. Following these early animal studies, various clinical trials have been done with the striatal implementation of human fetal DA neurons. Patients with human fetal ventral mesencephalon (VM) grafts have been shown to recover from rigidity and tremors to various degrees [15-18]. Though the outcome of striatal implantation of human fetal DA neurons in a large group of PD patients was very promising, the positive results of these initial clinical trials sharply contrasted with the results of large double-blind controled NIH studies, which failed to show any significant benefit in PD patients up to 1 and 2 years after implantation of DA neurons [1921]. Apart from human fetal DA neurons, several other sources for implantable human DA neurons have been explored. Notably, the induced pluripotent stem (iPS) cells generated from easily accessible somatic cells have provided an unprecedented novel autologous source for human DA neuron grafts [22-24]. The functionality of these in vitro generated human DA neurons after intrastriatal implantation have been recently studied in rodent and non-human primate models for PD. For example, human mesenchymal stromal cells (hMSCs) or human mesenchymal stem cells were reported to differentiate into different types of cells including DA neurons. As such, they are suitable for repairing the neural degeneration and traumatic damages of nerve system [2527]. Even though the human mesenchymal stromal cells are often used as human mesenchymal stem cells in some studies, scientifically they are different. The mesenchymal stromal cells should be the plastic-adherent cells with multipotency whereas mesenchymal stem cells should be a subset of human mesenchymal stromal cells that that can generate fibroblast colonies (CFU-F) in vitro. Thus the mesenchymal stem cells account for a small fraction of mesenchymal stromal cells with stem cell activity [28-30].

The hMSCs reside in all organs and tissues including bone marrow, muscle, brain, skin, dental pulp, adipose tissue, and umbilical cords. The bone marrowderived mesenchymal stem cells (BM-MSCs) were shown to differentiate into DA neurons and alleviate the motor deficits in PD rats $[1,31]$. Similarly, human umbilical cord-derived mesenchymal stromal cells (hUC-MSCs) and human umbilical cord blood-derived mesenchymal stem cells (hUCB- MSCs) share most characteristics of BM-MSCs and could improve the behavior abnormalities in animal models of neurological diseases [32, 33]. In two of our recent studies, transplantation of human umbilical cord blood-derived mononuclear cells (hUCBMNCs) improved the clinical symptoms of patients with delayed encephalopathy after carbon monoxide intoxication and restored the functional defects in the 6-OHDA-lesioned rats [26, 34]. Here we examined the functionality of DA neurons differentiated from hUCMSCs in unilateral 6-OHDA lesioned rat model of PD. By taking advantage of a novel floor-plate (FP) human pluripotent stem cells (PSCs) differentiation protocol that faithfully recapitulates midbrain DA neuron development $[3,35]$, we demonstrated a highly efficient DA neuronal conversion from hUC-MSCs by treating the hUC-MSCs with Noggin, SHH and FGF8 in early stage of cell differentiation and adding CHIR99021 in the middle stage of differentiation. Then we transplanted the hUCMSCs and the growth factor cocktail containing noggin, CHIR99021, SHH, FGF8, TGF- $\beta$, GDNF, and BDNF into the lesion side of the midbrain of 6-OHDA lesioned rats. The results of behavioral tests and immunofluorescent staining at different post-graft time points, plus the electrophysiological recording data, indicate a highly efficient DA neuronal conversion of hUC-MSCs in vitro and the functional recovery of the 6-OHDA lesioned PD rats.

\section{RESULTS}

\section{The isolated human umbilical cells specifically express the surface markers of MSCs}

The human umbilical cords were collected and cut into small clumps, which were first grown in human MSC culture medium (DMEM/F12, FBS, glutamine, NEAA and $\mathrm{P} / \mathrm{S}$ ) for 7-14 days. The cells of the clumps showed typical fibroblast morphology, similar to skin fibroblasts or BM-MSCs (Figure 1A-1C). These cells were passaged 
every week when they reach $90 \%$ confluence. Cells at passages 5-8 were subjected to flow cytometry analysis to detect the expression of cell surface antigens. All hUCMSCs highly expressed CD29 (99.9\%), CD73 (93.4\%) and CD90 (99.9\%), all of which are the surface markers of MSCs. They also expressed monocyte marker CD16 at a lower level (3.6\%). But, these cells showed only very low expression of CD34 (0.1\%) and CD45 (0.4\%), two markers of hematopoietic stem cell (Figure 1D).

\section{Highly efficient DA neuronal conversion of hUC- MSCs in vitro and in 6-OHDA lesioned rats}

To increase conversion of hUC-MSCs to neurons and DA neurons, we have modified a previously reported protocol $[3,35]$ by treating the hUC-MSCs with Noggin,
SHH and FGF8 in early stage of cell differentiation and adding CHIR99021 in the middle stage of differentiation as shown in Figure 2A. After being cultured for 21 days with the modified protocol, almost all the cells had the morphology of neural cells with apparent cell processes (Figure 2B-2C). Most expressed neuronal markers of Tuj1 $(77.0 \pm 2.1 \%)$ or MAP2 $(73.1 \pm 2.9 \%)$; some were positive for TH $(36.3 \pm 1.8 \%)$ and DAT $(34.6 \pm 1.7 \%)$. In contrast, cells that were not treated with growth cocktail factors containing noggin, CHIR99021, SHH, FGF8, TGF- $\beta$, GDNF, and BDNF did not show similar neuronal markers (Figure 2C-2D). DA release was greatest at 14 and 21 days of culturing (Figure 2E). The patch-clamp analysis showed growth cocktail-induced hUC-MSCs have the electrophysiological profiles of DA neurons, which is different from that of control hUC-MSCs at spontaneous
A

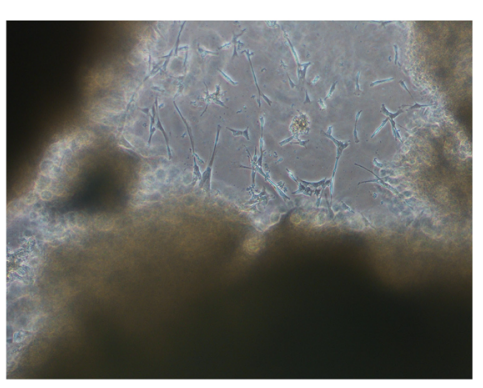

D
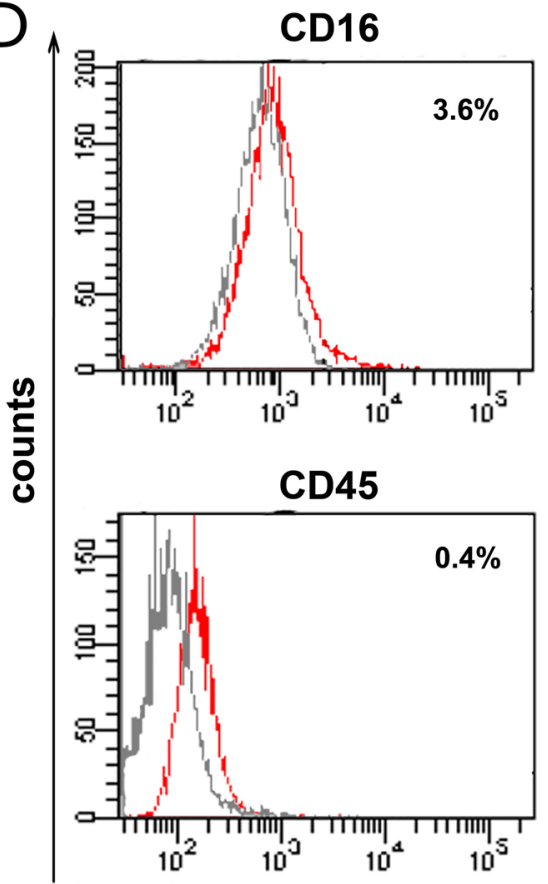
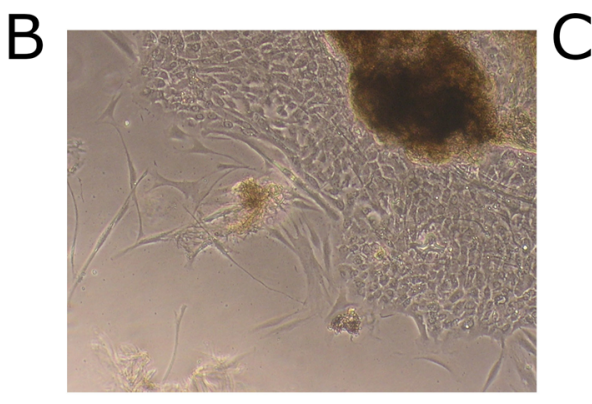

CD29
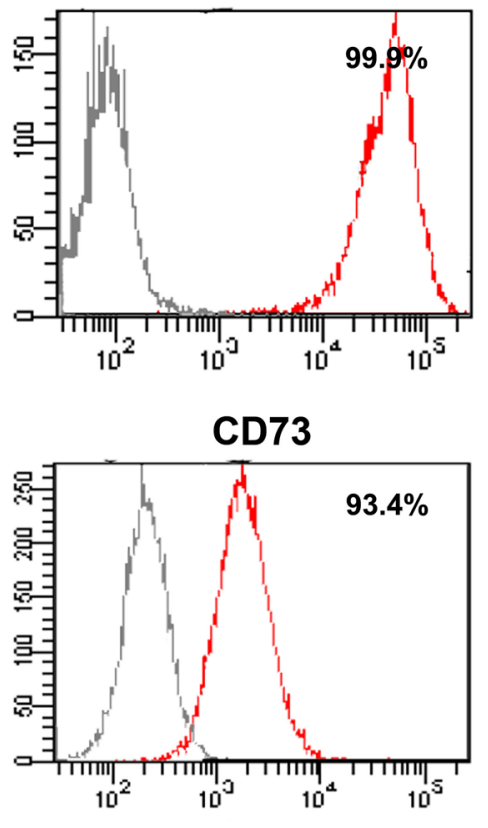

log fluorescence

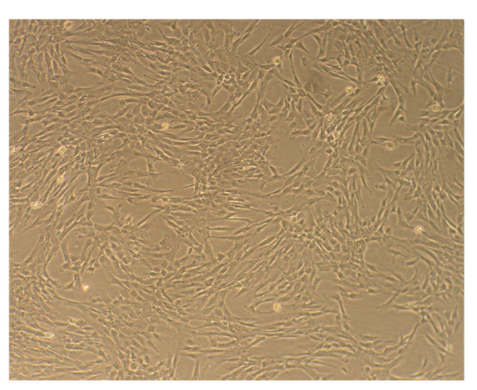

CD34
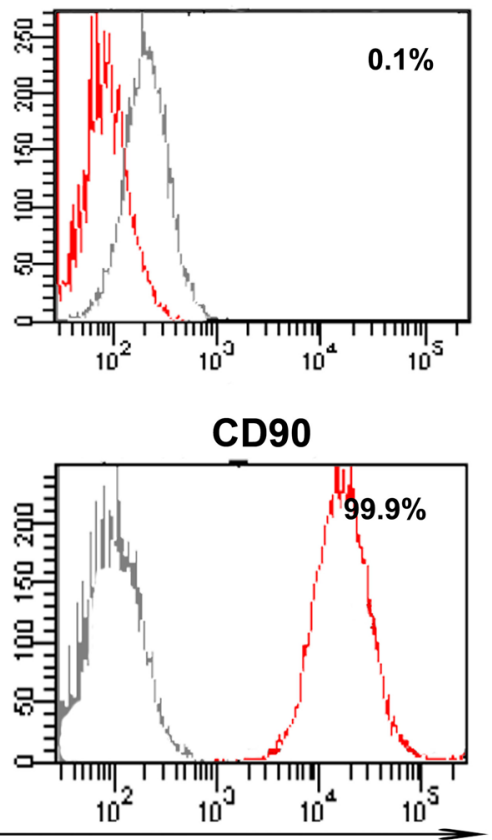

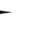


current and depolarizing current states (Figure 2F). These data indicated a highly efficient DA neuronal conversion of hUC-MSCs with the protocol used in this study.

\section{The grafted hUC-MSCs progressively improved motor behaviors of 6-OHDA lesioned rats}

Before transplantation, we examined if the 6-OHDA induced PD rats are depleted of the dopamine neurons and found that rats showed a dramatic loss of TH-positive neuronal fibers in SN of the lesion side compared to the intact side of the rats as previous reports four weeks after an unilateral intrastriatal injection of 6-OHDA [24, 36].

According to the previous studies using bone marrow MSCs for the treatment of PD, in the first transplantation experiment, we transplanted the hUC-MSCs to ten 6-OHDA lesioned rats (MSC group) and injected PBS with BDNF, GDNF to eight rats (control group) and followed 16
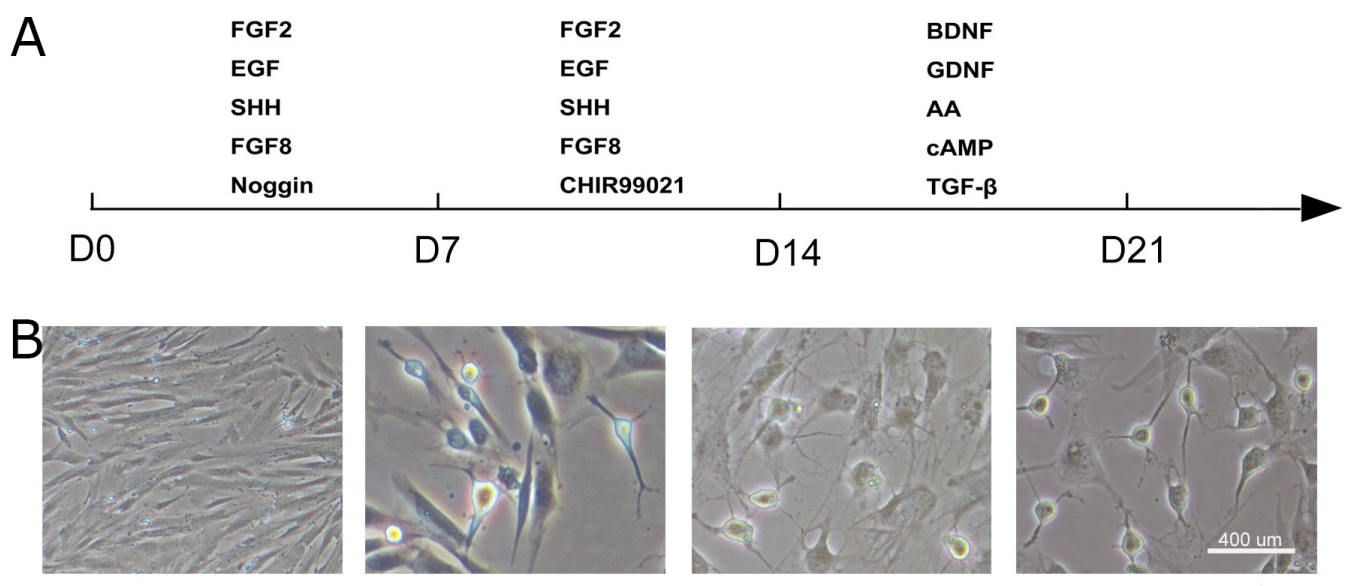

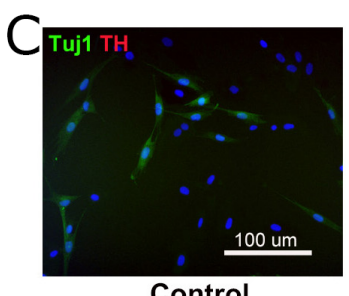

Control

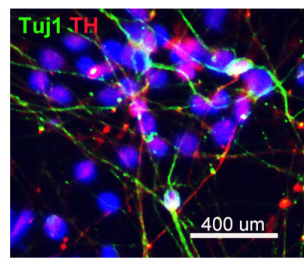

DA cocktail

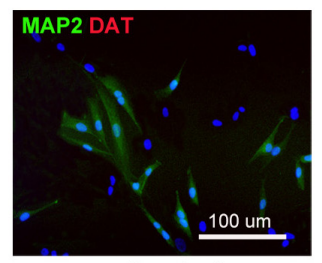

Control

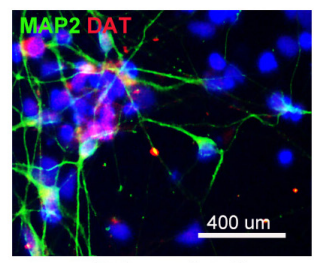

DA cocktail
D

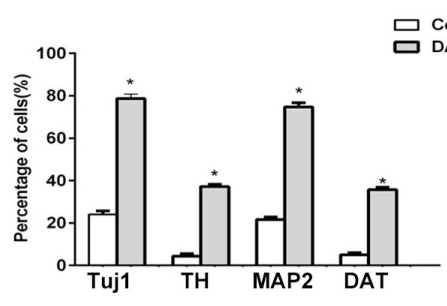

$F_{(i)}$

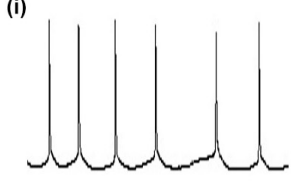

(ii)

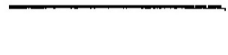

$E$
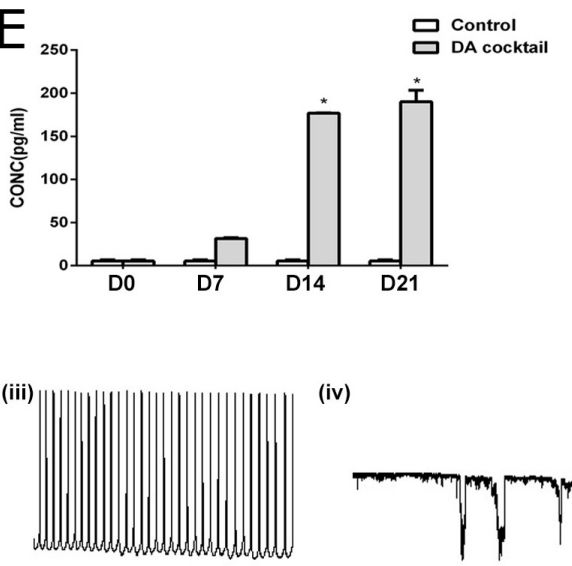

(iv)

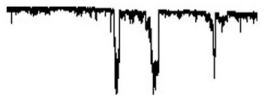

Figure 2: Directed dopamine neuronal differentiation from hUC-MSCs. (A) The protocol of hUC-MSCs differentiation. (B) Phasecontrast microcopy showed morphological changes of Differentiated neurons and dopamine neurons from hUC-MSCs. (C) Differentiated neurons and dopamine neurons from hUC-MSCs expressed neural marker Tuj1/TH and MAP2/DAT in control and DA cocktail medium (scale bar $=100$ $\mu \mathrm{m}$ ). (D) Quantification of neurons (Tuj1 and MAP2 staining) and dopamine neurons (TH and DAT staining) differentiated from hUC-MSCs in DA cocktail and control medium. $\mathrm{N}=5$, "Significant difference $(\mathrm{P}<0.05)$. (E) Dopamine secretion in control and DA cocktail medium. Data were expressed mean $\pm \mathrm{SD} . \mathrm{N}=3$, "Significant difference $(\mathrm{P}<0.05)$. (F) The patch-clamp analysis showed DA-cocktail-induced hUC-MSCs $(\mathrm{hUC}$ iDA) (iii, iv) have different electrophysiological profiles from control hUC-MSCs (i, ii) at spontaneous current and depolarizing current states. DA cocktail represents the growth factors added to the culturing medium of hUC-MSCs during the three stages of neural induction. 
weeks to measure the motor behaviors of the rats. Of note two rats with transplanted hUC-MSCs died in the early time and were excluded from the experiment. The transplanted hUC-MSCs did improve the locomotive defects of the rats, but these grafted hUC-MSCs rarely differentiated to the dopamine neurons (data was not shown).

In the second transplantation experiment, twenty four 6-OHDA lesioned rats were chosen for cell transplantation, eight of which were transplanted with hUC-MSCs and the growth cocktail into the lesioned side of striatum, eight of which were infused with the growth cocktail dissolved in PBS, while the remained eight rats were infused with PBS, BDNF and GDNF as the control group. Turning-over and rotation-rod tests were performed for all the four study groups at 4, 8, 12 and 16 weeks after transplantation. The 6-OHDA lesioned rats showed a high frequency of turning over after a subcutaneously injection of apomorphine $(0.25 \mathrm{mg} / \mathrm{ml})$. Two-way ANOVA revealed a significant difference $\left[\mathrm{F}_{(8,75)}=34.5, \mathrm{p}<0.0001\right]$ between the cell transplantation and recovery time after transplantation with respect to the apomorphine-induced turning-over (Figure 3A), indicating that the transplanted cells did improve this motor behavior of 6-OHDA lesioned rats and that the improvement effect was increased over time during the recovery period. This indication was confirmed by the Turkey`s post hoc comparisons showing the further improvement of the motor behavior at a later time point over an earlier time point during the recovery period [Control vs Growth factor (8-week), p < 0.05; Control vs Growth factor (4 week, 12-week, 16-week), p $>0.05$; hUC-MSC+Growth factor vs control (4-week), $\mathrm{p}$ $<0.05$; hUC-MSC+ Growth factor vs Control (8-week, 12-week, 16-week), $\mathrm{p}<0.0001]$. hUC-MSC+Growth factor vs Growth factor(4-week), p > 0.05; hUC-MSC+ Growth factor vs Growth factor(8-week, 12-week, 16week), $\mathrm{p}<0.0001]$. hUC-MSC+Growth factor vs hUCMSC control (4-week), $\mathrm{p}>0.05$; hUC-MSC +Growth factor vs hUC-MSC (8-week, 12-week, 16-week), p < 0.0001]. In addition, the 6-OHDA lesioned rats showed a dramatic decrease in the latency to fall from a rotating rod compared to rats in Control and Growth factor groups. Two-way ANOVA revealed a significant interaction $\left[\mathrm{F}_{(8,40)}\right.$ $=16.7, \mathrm{p}<0.0001]$ between the cell transplantation and recovery time after transplantation with respect to this measurement (Figure 3B), indicating that the transplanted cells did improve this motor behavior of 6-OHDA lesioned rats and that the improvement effect increased over time during the recovery period by Turkey`s post hoc analysis [Control vs Growth factor (4-week,8-week), $\mathrm{p}<0.05$; Control vs Growth factor (12-week, 16-week), $\mathrm{p}>0.05$; hUC-MSC+Growth factor vs Growth factor (4week), $\mathrm{p}>0.05$; hUC-MSC +Growth factor vs Growth factor(8-week), $\mathrm{p}<0.01$; hUC-MSC +Growth factor vs Growth factor (12-week, 16-week), p < 0.0001]; hUCMSC +Growth factor vs hUC-MSC control (4-week, 8 week), $\mathrm{p}>0.05$; hUC-MSC +Growth factor vs hUC-MSC control (12 week), $\mathrm{p}<0.05$; hUC-MSC +Growth factor vs hUC-MSC control (16 week), $\mathrm{p}<0.0001$. These results indicated that transplantation of hUC-MSC+Growth factor significantly improved the motor deficits of the 6-OHDA lesioned rats compared to transplantation of hUC-MSC control, Growth factor and the control respectively.

\section{The persistent and high survival rate of hUC- MSCs and differentiated DA neurons in the lesioned SN of 6-OHDA lesioned rats}

We transplanted the undifferentiated hUC-MSCs, plus the growth factor cocktail, into the 6-OHDA lesioned striatum of rats. We examined whether the transplanted hUC-MSCs survived and differentiated into neurons and DA neurons in the 6-OHDA lesioned rats. Sixteen weeks after hUC-MSCs transplantation, most of grafted cells were positively labeled by the antibody to Tuj1, indicating a highly efficient neuronal conversion of the transplanted cells in vivo (Figure 4A). More importantly, nearly half (about 44\%) of the Tuj1 neurons co-expressed TH, the specific marker of DA neurons (Figure 4A-4D). To rule out the possibility that the surviving cells were from the host rat brain, a human specific antibody (HNuc) was used to label the grafted cells. It was shown that a considerable percent of the HNuc-positive cells were also TH-positive, confirming that the TH-positive cells were mainly from transplanted human hUC-MSCs (Figure 4B-4D). Interestingly, the number of GFAP-positive cells was more than that of the HNuc-positive cells in the lesion site of the striatum (Figure 4C-4D). Confocal microscope images further confirmed the co-immunostaining of the Tuj1 and TH, $\mathrm{TH}$ and HNuc, GFAP and HNuc (Figure 4E-4G).

To understand the dopamine neuron differentiation ability of grafted hUC-MSCs with growth cocktail in different time points, the 6-OHDA lesioned rats were sacrificed at indicated time points $(4,8,12$ and 16 weeks) after transplantation. The numbers of HNuc remained at comparable levels across the first three time points while that at the last time point (16 weeks after transplantation) showed a slight but significant decrease. Similarly, numbers of TH-positive neurons co-labeled with HNuc were comparable at all time points except for the last time point, at which TH-positive neurons derived from transplanted cells decreased significantly (Figure 5). Since the grafted cells are clustered in the rat brains, the morphologies of these cells seem to be blurring. However some grafted cells at the time point of 16 weeks did have the neurites or processes as indicated by white arrows at the bottom of Figure 5.

\section{The hUC-MSCs derived neurons in 6-OHDA lesioned rats show typical electro- physiological recordings of DA neurons}

To further examine if the differentiated DA neurons from hUC-MSCs could function as typical DA neurons, 
cell patch-clamp test was performed to record the action potentials of the DA neurons from rats sacrificed at 16 weeks after the transplantation. We had tried to label the hUC-MSCs with lentiviral plasmids to express GFP, but our GFP-labeled cells lose the fluorescence in 2 weeks as we reported in our previous study. Then we decide to transplant the un-labeled hUC-MSCs. Even though the transplanted hUC-MSCs were not labeled with GFP or other fluorescence protein, most of the transplanted hUC-
MSCs in rat brain are clustered as we saw in Figure 3. Thus on brain slices, transplanted cells have clear edges with the host cells and can be identified from the host cells under the microscopy. Based on the morphologies of the transplanted cells, we picked several cells (hUC-MSC-induced dopamine neuron-like cells) to do the patch-clamp analysis. As shown in Figure 6, a characteristic Ih voltage sag and spontaneous rebound spiking activity of a neuron were current-clamped at $-60 \mathrm{mV}$, followed by a $5-\mathrm{s},-200-\mathrm{pA}$ current injection. The
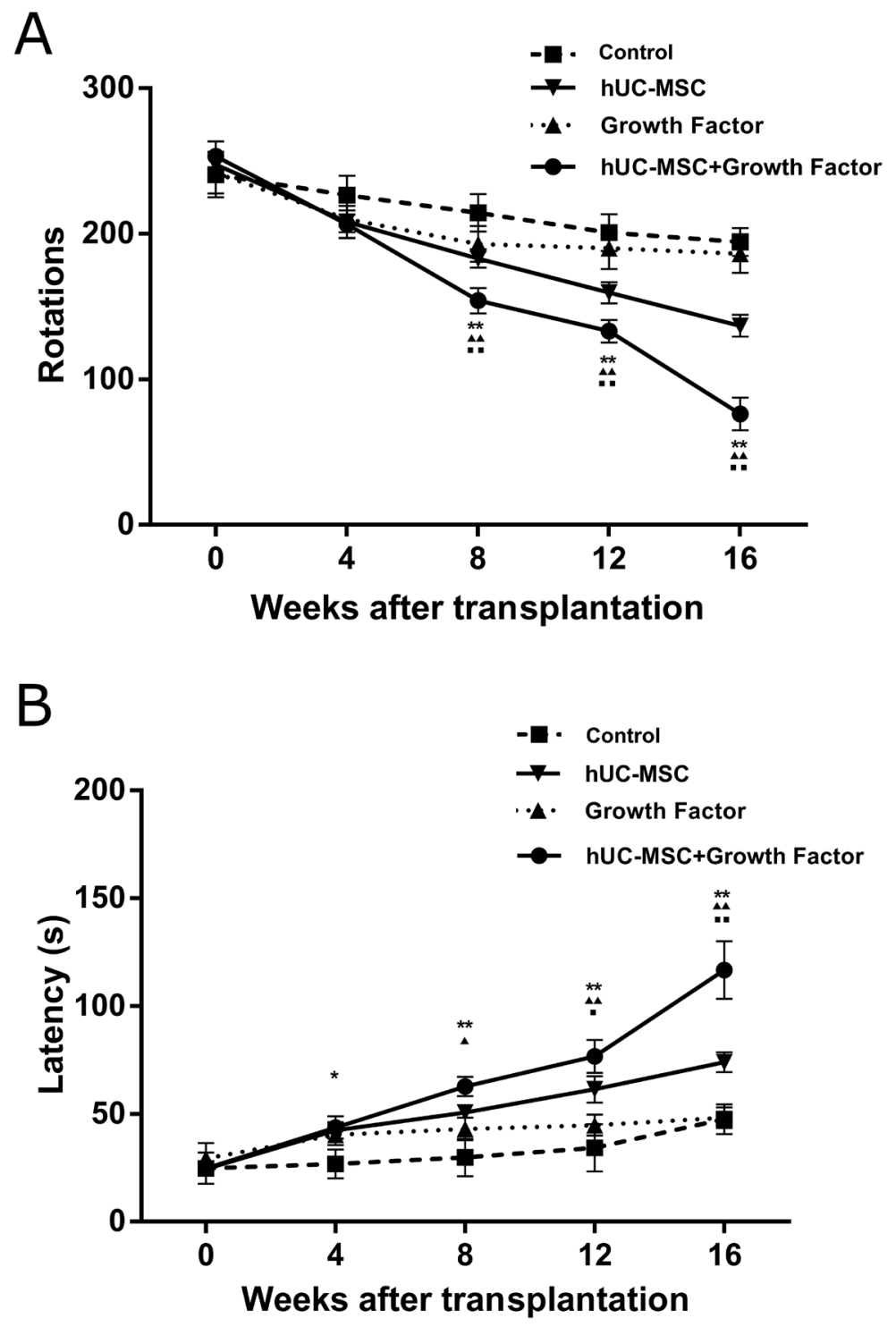

Figure 3: The progressive improvements on motor behaviors of 6-OHDA-lesioned rats with transplanted hUC-MSCs. (A) The frequency of apomorphine-induced rotations (turning-over) was significantly reduced in rats with transplanted hUC-MSCs+growth factor cocktail compared to control rats (PBS injection), growth factor rats (cocktail injection) and the transplanted hUC-MSCs (MSC control) at the indicated time points during the post-grafting period. The frequency of apomorphine-induced rotations is significantly reduced in rats with transplanted hUC-MSCs+ growth factor cocktail compared to Control group $\left({ }^{*}, \mathrm{P}<0.01 ;{ }^{* *}, \mathrm{P}<0.0001\right)$ Growth factor group $(\boldsymbol{\Delta}, \mathrm{P}<0.01 ; \boldsymbol{\Delta} \boldsymbol{\Delta}$, $\mathrm{P}<0.0001)$ and the MSC control $(\boldsymbol{\square}, \mathrm{P}<0.01 ; \boldsymbol{\square}, \mathrm{P}<0.0001)$ at 8,12 and 16 weeks after transplantation. Shown here are the average ratios of turning-over in 30 minutes after apomorphine injection over their standard deviations. (B) The rotation-rod test showed that the average latency for a rat to fall from a rotating rod in the group of transplanted hUC-MSCs+growth factor cocktail increased progressively at the indicated time points during the post-grafting period, and significantly longer than that of Control rats $\left({ }^{*}, \mathrm{P}<0.01 ;{ }^{* *}, \mathrm{P}<0.0001\right)$, Growth factor rats $(\boldsymbol{\Delta}, \mathrm{P}<$ 0.01; $\boldsymbol{\Delta} \boldsymbol{\Delta}, \mathrm{P}<0.0001)$ and MSC control $(\boldsymbol{\square}, \mathrm{P}<0.01 ; \boldsymbol{\square}, \mathrm{P}<0.0001)$. Data were expressed as mean $\pm \mathrm{SD}$. $\mathrm{N}=8$. 
slow pacemaker activity (Lower-left panel) and a broad action potential (Lower-right panel) reflect the existence of typical DA neurons. Moreover, representative electrode recordings of DA overflow in response to 10-s stimulation with 50-mM K+ in hUC-MSC striatal slices were presented. No action potentials were recorded in the 6-OHDA lesioned site of rats with infusion of PBS only (not shown). These electrophysiological recordings further supported the grafted hUC-MSCs were converted to dopamine neuron-like cells to function in vivo.

\section{DISCUSSION}

In the present study we isolated hUC-MSCs from human umbilical cords and induced their neuronal differentiation by the addition of the growth factor cocktail containing Noggin, CHIR99021, SHH, FGF8, TGF- $\beta$, GDNF, and BDNF. The hUC-MSCs highly expressed CD90 and CD73, similar to the expression of these surface markers by BM-MSCs which have been shown to differentiate into DA neurons and alleviate the
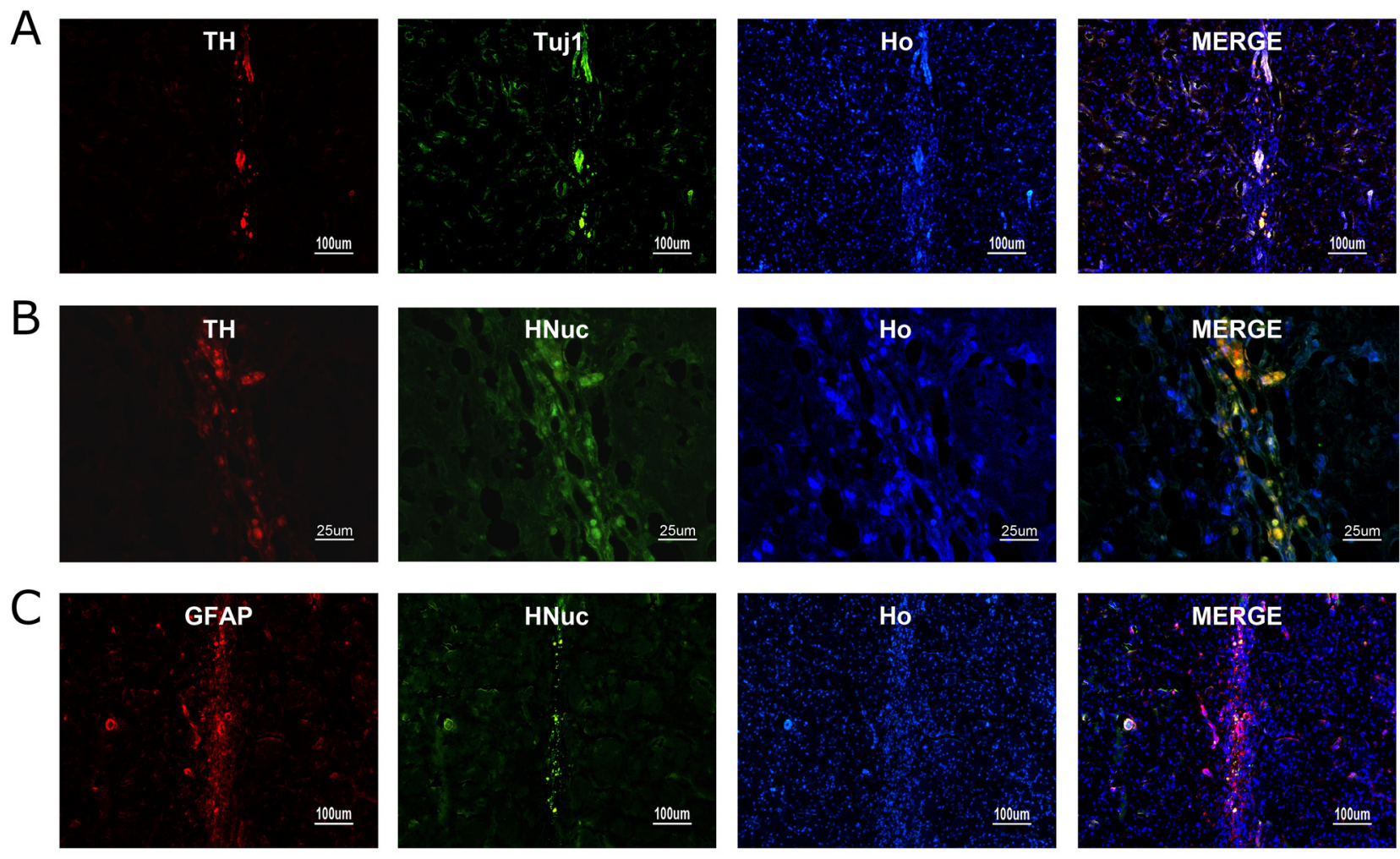

D
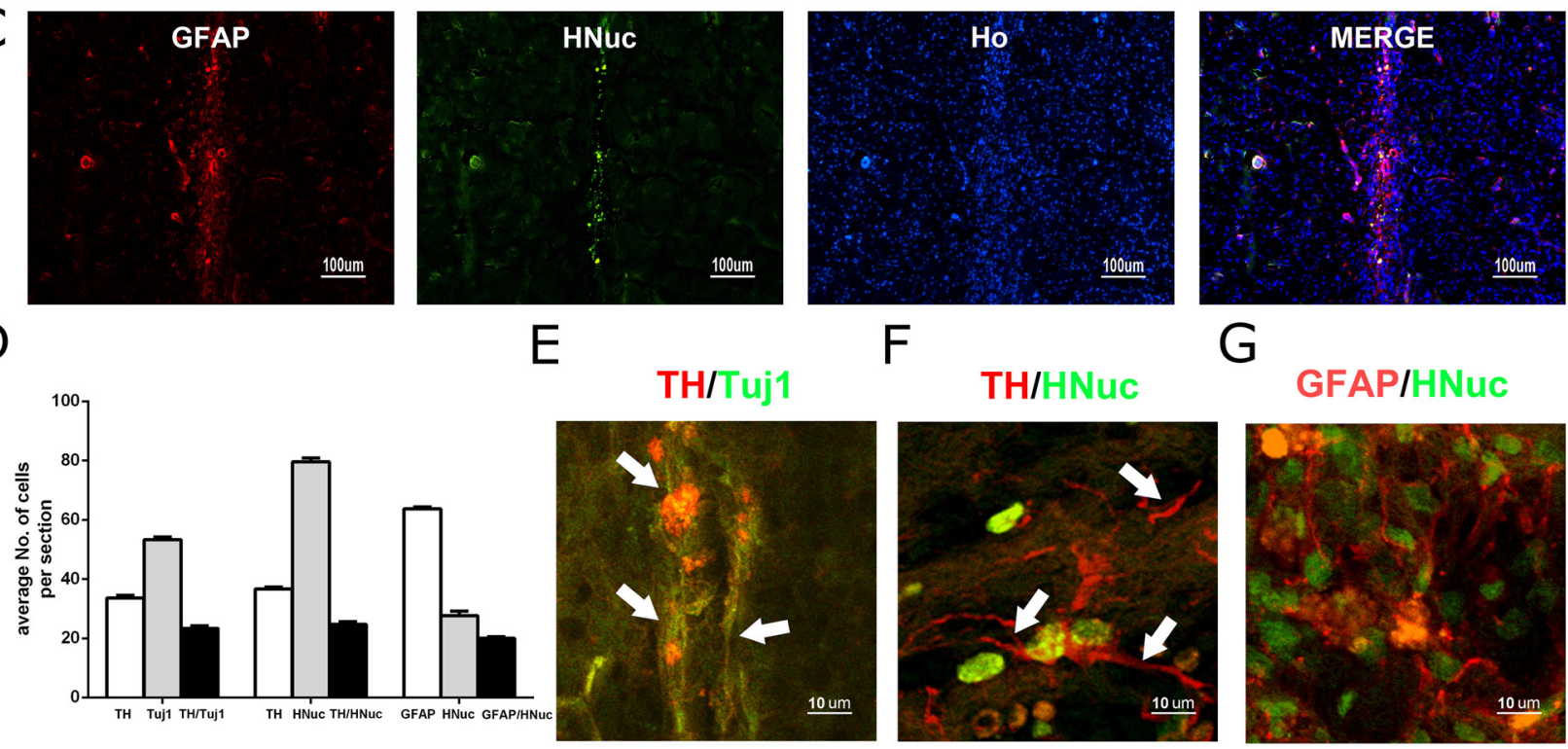

G
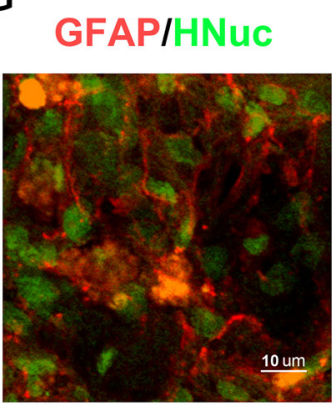

Figure 4: The long-term survival of grafted hUC-MSCs and DA neurons derived from hUC-MSCs in the striatum of 6-OHDA-lesioned rat. (A) hUC-MSC grafts immunostained for TH (red), TUJ1 (green), Hoechst 33258 (blue) 16 weeks after transplantation. (B) hUC-MSC grafts immunostained for TH (red), human nuclear antigen (HNuc) (green), or Hoechst 33258 (blue) 16 weeks after transplantation. (C) hUC-MSC grafts immunostained for GFAP (red), HNuc (green), or Hoechst 33258 (blue) 16 weeks after transplantation (Ho represents Hoechst staining for nuclei. (D) The quantification of positively labeled cells. (A, C): scale bar $=50 \mu \mathrm{m}$; (B): scale bar $=100 \mu \mathrm{m}$. (E, F, G) Confocal microscope images co-immunostained for Tuj1 and TH, TH and HNuc, GFAP and HNuc. The neurites or processes of the differentiated dopamine neurons are indicated by white arrows. Scale bar $=10 \mu \mathrm{m}$. Data were expressed mean $\pm \mathrm{SD}$. $\mathrm{N}=5$. 


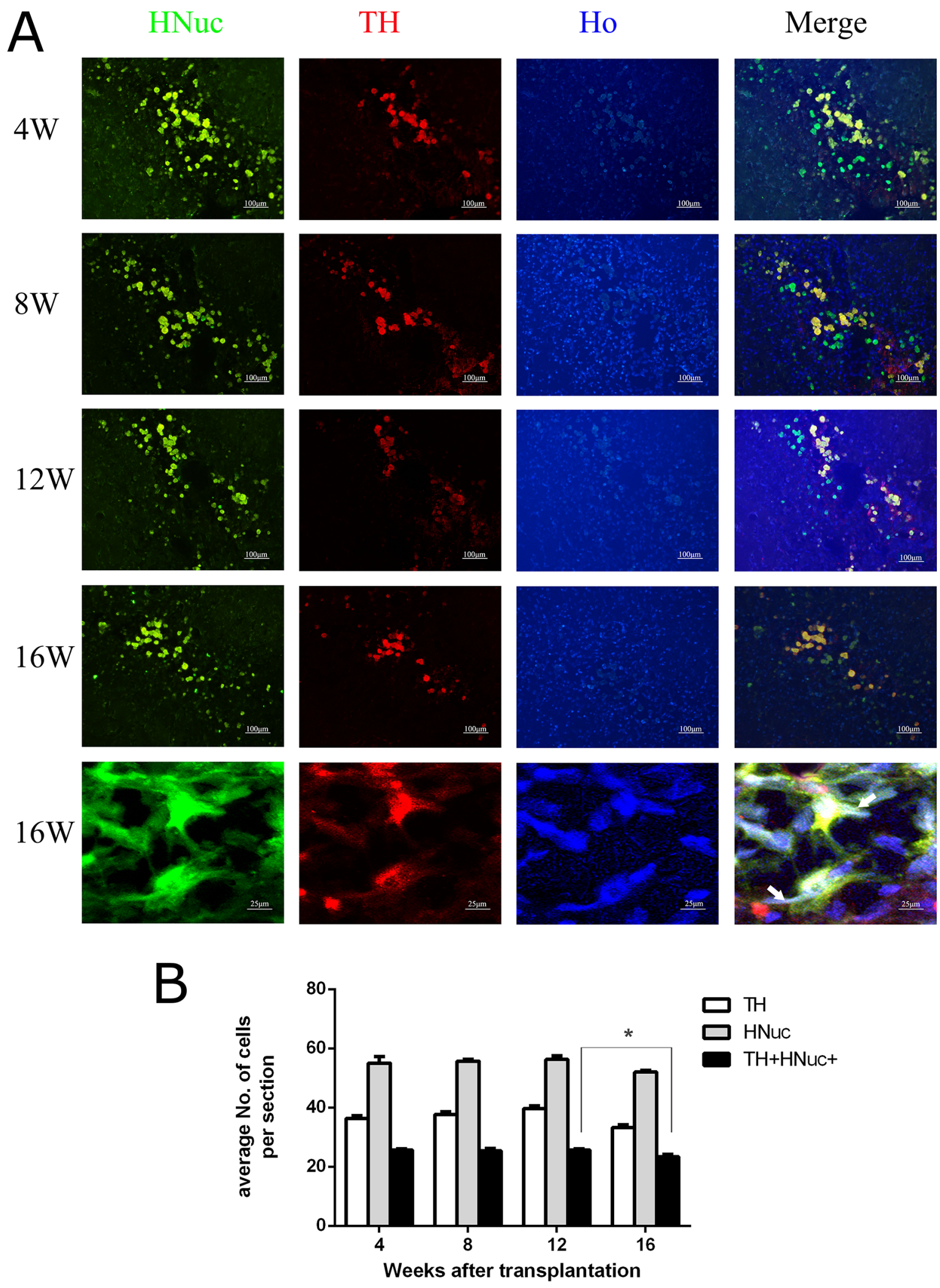

Figure 5: The persistent in vivo survival of DA neurons from transplanted hUC-MSCs. (A) Representative images showing TH-labeled neurons and HNuc-positive cells in the transplantation site of 6-OHDA lesioned rats sacrificed at the indicated time points during post-grafting period. (B) The quantification of positively labeled cells. scale bar $=100 \mu \mathrm{m}$. Data were expressed as mena \pm SD. $\mathrm{N}=5$. ${ }^{*}, \mathrm{P}<0.05$. 
motor deficits in PD rats [1, 31]. Moreover, the growth cocktail used in this study efficiently induced neuronal differentiation and DA neuronal conversion from hUCMSCs. Specifically, 77\% of hUC-MSCs derived cells were Tuj 1 positive; $73 \%$ of them were MAP2 positive. $36 \%$ of hUC-MSCs derived cells were differentiated into TH positive neurons (Figure 2). This number is higher than those reported in previous studies. Examples include a study by Hargus et al [37], who reported that $5-10 \%$ of the total number of differentiated cells derived from iPS cells. Rhee et al [38] reported that $50-60 \%$ of all differentiated cells were Tuj1 positive, of which $35-45 \%$ were $\mathrm{TH}$ positive, lower than the differentiation ratio reported in this study. More importantly, the grafted hUC-MSCs showed high neuronal differentiation in the 6-OHDA lesioned rats, as evidenced by the findings that $56 \%$ of all differentiated cells were Tuj 1 positive, and 36\% were TH positive (Figure 4). These results provided supporting evidence for the application of the growth factor cocktail protocol in the transplantation of hUC-MSCs in 6-OHDA lesioned rats, a commonly accepted animal model of PD.

The importance and advantage of the combination of hUC-MSCs and the growth cocktail can be also recognized by comparing the results of this study with other studies with BM-MSCs, most of which added SHH and FGF8 in the middle and late stages of neural induction for a period of 14 or 21 days. Only a few percentage of DA neurons were produced from BM-MSCs in these previous studies $[39,40]$. Although the mechanisms for the different ratios of neuronal differentiation between this study and previous ones were not specifically addressed in this study, the following details may be relevant: firstly, we used the BMP inhibitor noggin to inhibit the SMAD signaling inspired by the previous report that the inactivation of BMP signaling pathway was able to induce neural conversion in early progenitor stage [35]; secondly, we added CHIR99021 in middle stage of dopaminergic induction to activate the Wnt signaling of the cell fate
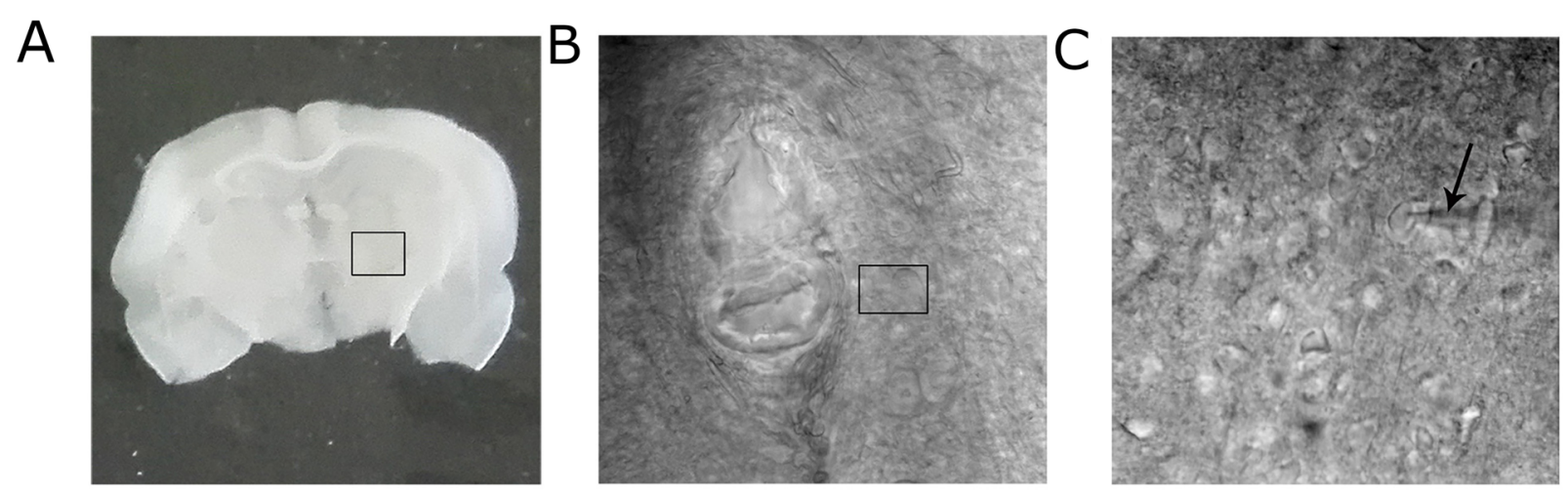

D

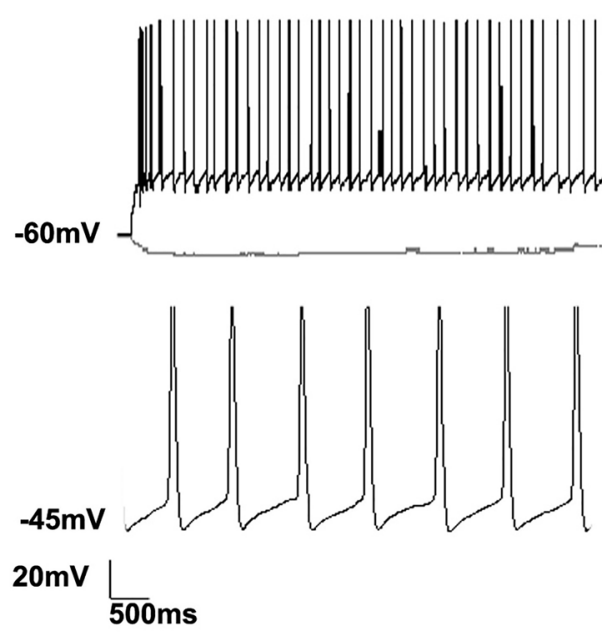

E

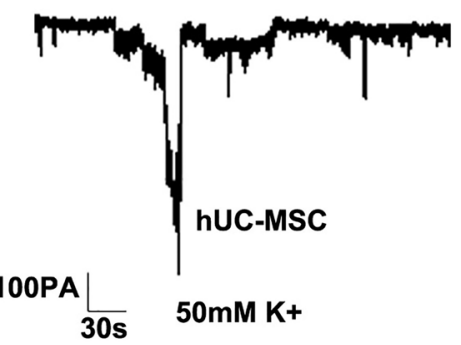

Figure 6: The electrophysiological recordings of differentiated neurons from grafted hUC-MSCs in a 6-OHDA lesioned rat. (A) A coronal brain slice $(350 \mu \mathrm{m})$ through the striatum where hUC-MSCs were grafted. (B) The enlargement of the marked area in image A showing the transplantation track. (C) The enlargement of the marked area in image B showing the position of a high-resistance pipette. (D) Representative current-clamp voltage traces of electrophysiological recordings of a neurons from grafted hUC-MSCs. Characteristic Ih voltage sag and spontaneous rebound spiking activity of a neuron (Upper panel) was current-clamped at -60 mV, followed by a 5-s, -200-pA current injection. Slow pacemaker activity (Lower-left panel) and broad action potentials (Lower-right panel) are characteristic of DA neurons. (E) Representative electrode recordings of DA overflow in response to 10 -s stimulation with $50-\mathrm{mM} \mathrm{K}+$ in hUC-MSCs rat striatal slices. 
and increase the production of midbrain progenitors as reported previously [41, 42]; thirdly, we also added $\mathrm{SHH}$ and FGF8 to the induction medium. The combination of Noggin, CHIR99021, SHH and FGF8 may efficiently promote the hUC-MSCs to convert into neurons and DA neurons.

The second significant finding of this study is that most of the transplanted hUC-MSCs and DA neurons differentiated from these grafted cells survive during the 16 weeks post grafting (up to $30 \%$, Figure 4). This is in contrast to the very low percentages of surviving DA neurons (from $0 \%$ to $1.1 \%$, and $5-10 \%$ ) reported in previous studies $[37,38,43]$. These previous studies executed transplantation at the late stage of terminal differentiation whereas we transplanted hUC-MSCs at the early stage of dopaminergic differentiation when the neural precursor cells are the predominant part [43]. Such grafted neural precursor cells already destined towards a VM DA neuron fate but could still proliferate before final differentiation into mature DA neurons in situ and give rise to a much larger number of $\mathrm{TH}$ positive cells as reported in other studies [3, 38, 41].

The transplanted hUC-MSCs and DA neurons differentiated from them progressively improved the motor behaviors of 6-OHDA lesioned rats as evidenced by decreases in the apomorphine-induced turning-over and increases in the latency to fall from a rota-rod. This finding is of clinical relevance and holds a great promise for future clinical applications. In support of this claim, the electrophysiological recordings indicated that the differentiated DA neurons in the 6-OHDA lesioned rats seems to play some function as the mature DA neurons in the brain, as evidenced by a characteristic Ih voltage sag and spontaneous rebound spiking activity of a neuron current-clamped at $-60 \mathrm{mV}$, as well as the representative electrode recordings of DA overflow in response to 10 -s stimulation with $50-\mathrm{mM} \mathrm{K}+$ in hUC-MSC striatal slices. These electrophysiological characteristics of DA neurons are unlikely produced from the host brain neurons as no action potentials were recorded in the 6-OHDA lesioned sites of rats with infusion of PBS only. Importantly, the improvement of motor function in group of transplanted hUC-MSC with growth factor cocktail is significantly higher than that of the hUCMSC control, or growth factor group or PBS control group after 8 weeks of transplantation, suggesting growth factor cocktail increased the neuronal and dopamine neuron differentiation of hUC-MSC and the functional connections between the grafted cells and the host neurons.

Recent studies have showed the human somatic cells were able to reprogrammed to induced pluripotent stem cells (iPS Cells) or somatic fibroblast cells were directly reprogrammed to neural stem cells or neurons [22, $24,44,45]$. Thus even though the MSCs are mesoderm lineage cells, they were definitely able to be induced to epidermal lineage cells such as the neurons. MSCs have been reported to be induced to dopamine neuron-like cells in several studies [46-48]. Some studies suggested the molecular mechanisms are through the epigenetic modifications such as inhibition of glycogen synthase kinase-3 $\beta$ and SMAD signaling [49]. In our study we did not transfer any genes into the hUC-MSC cells to induce their conversion to dopamine neurons, thus the mechanism is most possibly through epigenetic reprogramming of the components of the cocktail such as the inhibition of the SMAD signaling by noggin and the activation of the Wnt signaling by CHIR99021 as indicated by Studer [35]. We have not investigated the epigenetic mechanisms through which hUC-MSCs were induced to dopamine neuron-like cells in this study, but we will explore the mechanisms of this conversion in detail in the next studies.

In summary, isolated human umbilical cells specifically expressed the surface markers of MSCs and showed a high efficient DA neuronal conversion in vitro with addition of the growth factor cocktail containing noggin, CHIR99021, SHH, FGF8, TGF $\beta$, GDNF, and BDNF. In combination with the growth cocktail, grafted hUC-MSCs also showed a high efficient DA neuronal conversion in the midbrain of 6-OHDA lesioned rats. Both the grafted hUC-MSCs and the differentiated TH-positive neurons survived and displayed the same electrophysiological profile as DA neurons in vivo. More importantly, rats with transplanted hUC-MSCs showed progressive improvements on motor behavioral abnormalities induced by 6-OHDA during the up to 16 weeks post-grafting period. These results demonstrated the efficacy and usefulness of the growth cocktail in combination with hUC-MSCs transplantation in 6-OHDA lesioned rats and provided a promising cell-based therapy for the treatment of PD and other neurodegenerative diseases.

\section{MATERIALS AND METHODS}

\section{Human samples and ethics statement}

Human umbilical cords or hUC-MSCs preparation were obtained from healthy full-term newborns immediately after delivery, and this was performed in accordance with the Declaration of Helsinki and approved by the ethical guidelines of the Institutional Review Board at Liaocheng University/The Liaocheng People's Hospital, China. Informed consent forms were completed and signed by donor mothers before umbilical cords were collected.

\section{Isolation, culturing and flow cytometry analysis of hUC-MSCs}

Isolation and culture of hUC-MSCs was performed as described previously [32]. The isolated hUC-MSCs 
were cultured in human MSC culture medium and analyzed with a FACS Calibur flow cytometry (BD Biosciences, San Jose, CA, USA). A standard procedure was performed to characterize the hUC-MSCs through the cell surface markers of CD16, CD29, CD45, CD73, CD90 and CD34 [24]. These antibodies were fluoresced in isothiocyanate (FITC)-conjugated anti-human CD16, and CD90, R-phycoerythrin (PE)-conjugated anti-human CD29, CD45, CD34, and CD73 (BD Biosciences).

\section{Neural induction of hUC-MSCs}

We modified a recently reported protocol [35, 39] to generate DA neurons from hUC-MSCs. In the stage one, hUC-MSCs were plated in 6-well plates pre-coated with poly-L-ornithine and Laminin (Sigma-Aldrich) at $1 \times 10^{5}$ cells/well and cultured in DMEM/F12, N2, P/S, FGF-2(10 ng/mL), SHH (100 ng/mL), Noggin (250 ng/ mL, (R\&D Systems, Inc. Minneapolis, MN, USA)), FGF8 and EGF (10 ng/mL) for 7 days. In the stage two, cells were switched to the medium containing DMEM/F12, N2, $\mathrm{P} / \mathrm{S}, \mathrm{SHH}(100 \mathrm{ng} / \mathrm{mL})$ (R\&D Systems, Inc. Minneapolis, MN, USA), FGF-8 (10 ng/mL, PeproTech, Inc, NJ, USA), CHIR99021 (R\&D Systems, Inc. Minneapolis, MN, USA), and $200 \mathrm{mM}$ AAP (Sigma) for another 7 days. In the stage three, medium was changed to DMEM/F12, N2, $\mathrm{P} / \mathrm{S}, 50 \mathrm{ng} / \mathrm{mL}$ glial-derived neurotrophic factor (GDNF), BDNF (50 ng/mL) (R\&D Systems), TGF- $\beta$ and $200 \mathrm{mM}$ AAP. Cells differentiated for 4-5 weeks and then were fixed for immunocytochemical characterization. DMEM/ F12, N2, P/S, FGF2, EGF are from Invitrogen (USA).

\section{6-OHDA-lesioned rat model of PD}

All animal experiments were carried out in accordance with local ethical guidelines and with the approval of the Animal Care and Use Committee of Liaocheng University/ The Liaocheng People's Hospital, China.

Sprague-Dawley male rats (200 -250 gram) were anesthetized with $5 \%$ isoflurane mixed in oxygen. The rats were fixed in a KOPF stereotaxic frame (David, Kopf Instruments, Tujunga, CA, USA), and $4 \mu \mathrm{l}$ 6-OHDA (4 $\mu \mathrm{g}$ / $\mu 1, \mathrm{H} 4381$; Sigma-Aldrich) dissolved in PBS with ascorbic acid $(0.2 \mathrm{mg} / \mathrm{mL})$ was injected into the right substantia nigra of the rat midbrain at the anterior-posterior (AP) location, $-2.0 \mathrm{~mm}$, lateral (L), $+2.5 \mathrm{~mm}$, vertical (V), -7.8 $\mathrm{mm}$ from the bregma. The injection was administered within 4 minutes at a rate of $1 \mu \mathrm{l} /$ minute and the needle of the Hamilton syringe was kept for 10 minutes following the last deposit to prevent back filling along the injection tract. The animals were allowed to recover after surgery and kept in the animal house.

\section{Cell transplantation}

The differentiated hUC-MSCs were collected and dissociated to single cells with TrypLE. In order to increase
DA neuron differentiation of transplanted hUC-MSCs, we added growth factor cocktail (in PBS) to resuspend cells. This growth cocktail contains noggin, CHIR99021, SHH, FGF8, TGF $\beta$, GDNF, and BDNF as used for DA neuron induction in vitro. The freshly isolated hUC-MSCs were diluted in PBS with this growth factor cocktail to yield a cell concentration of $1 \times 10^{5}$ cells per microliter. Five microliters of cell suspension with growth factor cocktail (hUC-MSCs + growth factor) or cell suspension in PBS (hUC-MSCs) or growth cocktail in PBS (growth factor) or PBS only (Control) was transplanted into the striatum $(\mathrm{AP}=+0.7 \mathrm{~mm}, \mathrm{~L}=+3 \mathrm{~mm}, \mathrm{~V}=-5 \mathrm{~mm})$ of the anesthetized PD model rats 4 weeks after 6-OHDA lesion using a Hamilton syringe (0.3- $0.5 \mathrm{~mm}$ in diameter) over a period of 5-10 minutes. To minimize immune rejection of the transplanted cells, immunosuppressive agent of cyclosporine A (10 mg/kg; Sigma) was injected (i.p.) 24 hours before transplantation and daily afterwards until the rats were sacrificed.

\section{Behavioral tests}

Apomorphine-induced rotation was carried out in a plastic bowl to record the turning-over of the rats 3 minutes after a subcutaneously injection of apomorphine $(0.25 \mathrm{mg} / \mathrm{ml}$; Sigma; dissolved in PBS with ascorbic acid). The number of complete $\left(360^{\circ}\right)$ turns in a 30 -minute period was counted. The same test was done before transplantation and at indicated time points $(4,8,12$, and 16 weeks) after transplantation. In the first test (before cell transplantation), animals with more than 200 asymmetric rotations in 30 minutes in response to apomorphine 4 weeks after 6-OHDA injection were used as recipients for cell transplantation.

Rotarod test was performed to record the latency time to fall from a rotating rod which was scored automatically in a rotarod system (Columbus Instruments, Columbus, USA). The rats were put on the rotarod which is spinning at low speed (2-4 rotation per minute) to train the rats. After 3-4 trials on the spinning rod at low speed, the rats were tested for the latency to fall (duration time) at a rotarod speed of 9 rotations per minute. Motor coordination of rats was evaluated by comparing the latency to fall over time on the very first trial.

\section{Electrophysiological recordings}

Electrophysiological properties of the hUCMSCs-derived DA neurons in vitro were examined using whole-cell patch-clamp recording techniques (Axon Instruments, UAS) [50-52]. The glass electrode were filled with intracellular solutions containing (in $\mathrm{mM}$ ) $\mathrm{KCl}$ 140 or K-gluconate 140 , Na+-HEPES 10, BAPTA 10 , and Mg2+-ATP 4 (pH 7.2, 290 mosm). Streptavidin-Alex Fluor 488 (1:1,000, Molecular Probes) was added to the recording solution. The bath solution contained (in $\mathrm{mM}$ ) 
$\mathrm{NaCl} 127, \mathrm{KH} 2 \mathrm{PO} 41.2, \mathrm{KCl} 1.9, \mathrm{NaHCO} 326, \mathrm{CaCl} 2$ 2.2, $\mathrm{MgSO} 41.4$, and glucose 10 and $95 \% \mathrm{O} 2 / 5 \% \mathrm{CO} 2$ (pH 7.3; 300 mosm). The glass electrode resistance was typically $1-5 \mathrm{M} \Omega$ and was compensated by $80 \%-90 \%$ using amplifier circuitry. Voltages were corrected and action potentials (APs) were examined in current-clamp mode. Spontaneous excitatory and inhibitory synaptic currents were characterized in voltage-clamp mode using $\mathrm{K}$-gluconate based pipette solution by giving $-40 \mathrm{mV}$ voltage limit.

For brain slices in vivo experiment, electrochemical amperometric current (Iamp) was performed as previously described [51, 52]. Rats were anesthetized with trichloroacetaldehyde hydrate and then transcardially perfused with $\sim 50 \mathrm{~mL}$ ice-cold aCSF (artificial cerebral spinal fluid) containing (in $\mathrm{mM}$ ) $126 \mathrm{NaCl}, 3 \mathrm{KCl}$, $1.25 \mathrm{NaH} 2 \mathrm{PO} 4,24 \mathrm{NaHCO}, 2 \mathrm{MgSO}_{4}, 2 \mathrm{CaCl}_{2}$ and 10 Glucose and saturated with $95 \% \mathrm{O} 2$ and $5 \% \mathrm{CO}_{2}$. The brain was rapidly removed and cut into horizontal slices $(350 \mu \mathrm{m}$ thick) in the same aCSF. The slices were maintained at a temperature of $25^{\circ} \mathrm{C}$ and were allowed to equilibrate in this medium for 1 hour prior to recording. Both channels of an Axoprobe 1A amplifier (Axon Instruments, Union City, CA, USA) were employed for amperometric recordings, which were made using glass microelectrodes containing aCSF (resistance 4-6 M $\Omega$ ). DA overflow was evoked by perfusion with $50 \mathrm{mM} \mathrm{K}+$ for 10 $\mathrm{s}$ and recorded by glass microelectrodes in the recording $\mathrm{aCSF}$ at room temperature. Amperometric signals were calibrated offline according to the standard curve of DA at $0.1,1,3$ and $5 \mu \mathrm{M}$ in the aCSF. All amperometric recordings are expressed as both amperometric current (Iamp) and DA overflow concentration [DA].

\section{Immunocytochemistry and immunofluorescent staining}

For immunocytochemistry, differentiated cells were fixed in 4\% paraformaldehyde (PFA) in PBS for 20 minutes at room temperature. After washing with PBS, the cells were incubated in a blocking buffer ( $5 \%$ goat serum, $5 \%$ donkey serum and $0.2 \%$ triton X-100 in PBS) for 45 minutes at room temperature, and were then incubated with primary antibodies. For immunofluoresent staining, after perfused with $4 \%$ PFA, the whole rat brain was removed and post-fixed in the same fixative for 24 hours. Subsequently brain samples were cryoprotected in $30 \%$ sucrose for 24-48 hours, embedded in Tissue-Tek OTC (Sakura Finetek, USA, Inc., Torrance, CA) and sectioned into $20 \mu \mathrm{m}$ thickness sections using a cryostat (Leika CM1950, Germany). One of every five brain sections containing SN was collected for immunofluorescent staining. The employed primary antibodies included: the human nucleous antibody (HNuc, mouse monoclonal, 1:500, Millipore), neuronal marker (Tuj1 and MAP2, mouse monoclonal, 1:500, Sigma), DA neuron marker
(TH, rabbit polyclonal, 1:250, Pel-reez), DAT (rabbit polyclonal,1:250, Sigma Aldrich), or astrocyte marker (GFAP, rabbit polyclonal 1:250, Dako). After incubation with a primary antibody at $4{ }^{\circ} \mathrm{C}$ overnight, sections were rinsed with PBS, then incubated with the fluorescencelabeled secondary antibody of Alexa Fluor 488-goat anti-mouse or Cy3-goat anti-rabbit (1:1000, Jackson Laboratories) for 3-4 hours, followed by incubation with Hoechest 33528 (1:10000, Sigma) for 2-5 minutes. All images were optimized by using a fluorescence microscope (Nikon Ti, Nikon Corporation, Tokyo, Japan) or a laser scanning con-focal microscope (Olympus Corporation, Tokyo, Japan).

\section{Image analysis}

All immunofluorescent staining of differentiated cells and brain sections were analyzed using the software Image J (1.48 version, NIH, USA). For immunofluorescent staining of differentiated cells, the data of each measurement was averaged from 5 images taken at $100 \mathrm{X}$ under identical conditions. With respect to the immunofluorescent staining of brain sections, measurements were made on three brain sections of each animal of five animals in a group. The parameters include the percentage of specifically labeled cells over the total number of nuclei (in immunocytochemistry characterization of differentiated cells) and the number of TH-positive cells per section (in immunofluorescent staining of brain section).

\section{Detection of the dopamine secretion}

The dopamine content was detected by DA ELISA Kit (E-EL-0046c, Elabscience, China). According the manufacturer's instructions, cell culture medium was collected, and centrifuged at $1000 \mathrm{~g}$ at $2-8^{\circ} \mathrm{C}$. Clear supernatant was pooled and OD value was measured immediately under the microplate reader at $450 \mathrm{~nm}$. The content of DA in the samples was then determined by comparing the OD of the samples to the standard curve.

\section{Statistical analysis}

Data is expressed as mean \pm sd and analyzed by two-way ANOVA (for behavioral data), one-way ANOVA (data of cell differentiation and TH-positive cells at postgraft time points), significant effects were then performed with the Turkey's post hoc multiple comparison test using GraphPad Prism 6. In all cases, differences were considered statistically significant at $\mathrm{p}<0.05$.

\section{Abbreviations}

PD: Parkinson's disease; DA: dopamine; hUC-MSCs: human umbilical cord mesenchymal stromal cells; VM: ventral mesencephalon; 6-OHDA: 
6-hydroxydopamine; NSCs: neural stem cells; hESCs: human embryonic stem cells; BM-MSCs: bone marrowderived mesenchymal stem cells; PBS: phosphatebuffered saline; FBS: fetal bovine serum; FGF8: fibroblast growth factor 8; SHH: sonic hedgehog; GDNF: glial cell line-derived neurotrophic factor; BDNF: brainderived neurotrophic factor; MAP2: micro-tubule associated protein 2; GFAP: glial fibrillary acid protein; EGF: epidermal growth factor; FP: floor-plate; PFA: paraformaldehyde; SN: substance nigra; TH: tyrosine hydroxylase; HNuc: human nuclear antigen; iPSCs: induced pluripotent stem cells.

\section{Author contributions}

F.B.H. designed the experiment; F.B.H., C.C., Q.F.C., S.L., J.D., X.J.L., S.C.W., N.Z., W.W., H.S., Y.W. performed the experiments; F.B.H., Q.F.C. and P.L. wrote the manuscript; F.B.H., C.C., Q.F.C., W.W., S.W.L., C.B.L. analyzed the data. All authors reviewed the manuscript.

\section{ACKNOWLEDGMENTS}

We would like to thank all the participants in the study. The authors are grateful to Dr. Haiyun Xu (Shantou University Medical College) for his help in preparing this manuscript.

\section{CONFLICTS OF INTEREST}

All the authors declare that they have no conflicts of interest.

\section{FUNDING}

This work was supported by The Science and Technology Developmental Fund of Shandong Province, China (2012GSF11808), National Natural Science Foundation of China (NSFC 81571241, 81271251) and Research award of Shandong Provincial Administration of Foreign Experts Affairs (SDPAFEA 2013HF).

\section{REFERENCES}

1. Cheng HC, Ulane CM, Burke RE. Clinical progression in Parkinson disease and the neurobiology of axons. Ann Neurol. 2010; 67: 715-25. https://doi.org/10.1002/ ana.21995.

2. Olanow CW, Obeso JA. Pulsatile stimulation of dopamine receptors and levodopa-induced motor complications in Parkinson's disease: implications for the early use of COMT inhibitors. Neurology. 2000; 55: S72-7; discussion S8-81.

3. de Rijk MC, Launer LJ, Berger K, Breteler MM, Dartigues JF, Baldereschi M, Fratiglioni L, Lobo A, Martinez-Lage
J, Trenkwalder C, Hofman A. Prevalence of Parkinson's disease in Europe: a collaborative study of populationbased cohorts. Neurologic Diseases in the Elderly Research Group. Neurology. 2000; 54: S21-3.

4. Hodaie M, Neimat JS, Lozano AM. The dopaminergic nigrostriatal system and Parkinson's disease: molecular events in development, disease, and cell death, and new therapeutic strategies. Neurosurgery. 2007; 60: 17-28; discussion 28-30. https://doi.org/10.1227/01. NEU.0000249209.11967.CB.

5. Barker RA, Barrett J, Mason SL, Bjorklund A. Fetal dopaminergic transplantation trials and the future of neural grafting in Parkinson's disease. Lancet Neurol. 2013; 12: 84-91. https://doi.org/10.1016/S1474-4422(12)70295-8.

6. Olanow CW, Watts RL, Koller WC. An algorithm (decision tree) for the management of Parkinson's disease (2001): treatment guidelines. Neurology. 2001; 56: S1-S88.

7. Fahn S, Oakes D, Shoulson I, Kieburtz K, Rudolph A, Lang A, Olanow CW, Tanner C, Marek K. Levodopa and the progression of Parkinson's disease. N Engl J Med. 2004; 351: 2498-508. https://doi.org/10.1056/NEJMoa033447.

8. Limousin P, Pollak P, Benazzouz A, Hoffmann D, Le Bas JF, Broussolle E, Perret JE, Benabid AL. Effect of parkinsonian signs and symptoms of bilateral subthalamic nucleus stimulation. Lancet. 1995; 345: 91-5.

9. Zhou CQ, Zhang JW, Wang M, Peng GG. Meta-analysis of the efficacy and safety of long-acting non-ergot dopamine agonists in Parkinson's disease. J Clin Neurosci. 2014; 21: 1094-101. https://doi.org/10.1016/j.jocn.2013.10.041.

10. Bakay RA, Fiandaca MS, Barrow DL, Schiff A, Collins DC. Preliminary report on the use of fetal tissue transplantation to correct MPTP-induced Parkinson-like syndrome in primates. Appl Neurophysiol. 1985; 48: 358-61.

11. Bjorklund A, Dunnett SB, Stenevi U, Lewis ME, Iversen SD. Reinnervation of the denervated striatum by substantia nigra transplants: functional consequences as revealed by pharmacological and sensorimotor testing. Brain Res. 1980; 199: 307-33. doi: 0006-8993(80)90692-7.

12. Bjorklund A, Stenevi U. Reconstruction of the nigrostriatal dopamine pathway by intracerebral nigral transplants. Brain Res. 1979; 177: 555-60. doi: 0006-8993(79)90472-4.

13. Perlow MJ, Freed WJ, Hoffer BJ, Seiger A, Olson L, Wyatt RJ. Brain grafts reduce motor abnormalities produced by destruction of nigrostriatal dopamine system. Science. 1979; 204: 643-7.

14. Redmond DE Jr, Sladek JR Jr, Roth RH, Collier TJ, Elsworth JD, Deutch AY, Haber S. Transplants of primate neurons. Lancet. 1986; 2: 1046. doi: S0140-6736(86)92664-4.

15. Freed CR, Breeze RE, Rosenberg NL, Schneck SA, Wells TH, Barrett JN, Grafton ST, Huang SC, Eidelberg D, Rottenberg DA. Transplantation of human fetal dopamine cells for Parkinson's disease. Results at 1 year. Arch Neurol. 1990; 47: 505-12. 
16. Lindvall $\mathrm{O}$, Brundin $\mathrm{P}$, Widner $\mathrm{H}$, Rehncrona $\mathrm{S}$, Gustavii B, Frackowiak R, Leenders KL, Sawle G, Rothwell JC, Marsden CD, Bjorklund A. Grafts of fetal dopamine neurons survive and improve motor function in Parkinson's disease. Science. 1990; 247: 574-7.

17. Lindvall O, Sawle G, Widner H, Rothwell JC, Bjorklund A, Brooks D, Brundin P, Frackowiak R, Marsden CD, Odin P, Rehncrona $\mathrm{S}$. Evidence for long-term survival and function of dopaminergic grafts in progressive Parkinson's disease. Ann Neurol. 1994; 35: 172-80. https://doi.org/10.1002/ ana.410350208.

18. Chen L, Huang H, Duan WM, Mao G. Clinical neurorestorative progress in Parkinson's disease. J Neurorestoratol. 2015; 3: 101-7. https://doi.org/10.2147/jn.s74144.

19. Redmond DE Jr, Sladek JR, Spencer DD. Transplantation of embryonic dopamine neurons for severe Parkinson's disease. N Engl J Med. 2001; 345: 146-7. https://doi. org/10.1056/NEJM200107123450214.

20. Bjorklund A, Kordower JH. Cell therapy for Parkinson's disease: what next? Mov Disord. 2013; 28: 110-5. https:// doi.org/10.1002/mds. 25343 .

21. Lindvall O, Bjorklund A. Cell therapy in Parkinson's disease. NeuroRx. 2004; 1: 382-93. https://doi.org/10.1602/ neurorx.1.4.382.

22. Takahashi K, Tanabe K, Ohnuki M, Narita M, Ichisaka T, Tomoda K, Yamanaka S. Induction of pluripotent stem cells from adult human fibroblasts by defined factors. Cell. 2007; 131: 861-72. https://doi.org/10.1016/j.cell.2007.11.019.

23. Takahashi K, Yamanaka S. Induction of pluripotent stem cells from mouse embryonic and adult fibroblast cultures by defined factors. Cell. 2006; 126: 663-76. https://doi. org/10.1016/j.cell.2006.07.024.

24. Han F, Wang W, Chen B, Chen C, Li S, Lu X, Duan J, Zhang Y, Zhang YA, Guo W, Li G. Human induced pluripotent stem cell-derived neurons improve motor asymmetry in a 6-hydroxydopamine-induced rat model of Parkinson's disease. Cytotherapy. 2015; 17: 665-79. https:// doi.org/10.1016/j.jcyt.2015.02.001.

25. da Silva Meirelles L, Caplan AI, Nardi NB. In search of the in vivo identity of mesenchymal stem cells. Stem cells. 2008; 26: 2287-99. https://doi.org/10.1634/ stemcells.2007-1122.

26. Chen C, Duan J, Shen A, Wang W, Song H, Liu Y, Lu X, Wang X, You Z, Han Z, Han F. Transplantation of human umbilical cord blood-derived mononuclear cells induces recovery of motor dysfunction in a rat model of Parkinson's disease. J Neurorestoratol. 2016; 4: 23-33. https://doi. org/10.2147/jn.s98835.

27. Al-Zoubi A, Altwal F, Khalifeh F, Hermas J, Al-Zoubi Z, Jafar E, El-Khateeb M. Ex vivo differentiation of human bone marrow-derived stem cells into neuronal cell-like lineages. J Neurorestoratol. 2016; 4: 35-44. https://doi. $\operatorname{org} / 10.2147 /$ jn.s101001.
28. Horwitz EM, Le Blanc K, Dominici M, Mueller I, Slaper-Cortenbach I, Marini FC, Deans RJ, Krause DS, Keating A. Clarification of the nomenclature for MSC: the international society for cellular therapy position statement. Cytotherapy. 2005; 7: 393-5. https://doi. org/10.1080/14653240500319234.

29. Dominici M, Le Blanc K, Mueller I, Slaper-Cortenbach I, Marini F, Krause D, Deans R, Keating A, Prockop D, Horwitz E. Minimal criteria for defining multipotent mesenchymal stromal cells. The international society for cellular therapy position statement. Cytotherapy. 2006; 8: 315-7. https://doi.org/10.1080/14653240600855905.

30. Galipeau J, Krampera M, Barrett J, Dazzi F, Deans RJ, DeBruijn J, Dominici M, Fibbe WE, Gee AP, Gimble JM, Hematti P, Koh MB, LeBlanc K, et al. International society for cellular therapy perspective on immune functional assays for mesenchymal stromal cells as potency release criterion for advanced phase clinical trials. Cytotherapy. 2016; 18: 151-9. https://doi.org/10.1016/j.jcyt.2015.11.008.

31. Kan I, Ben-Zur T, Barhum Y, Levy YS, Burstein A, Charlow T, Bulvik S, Melamed E, Offen D. Dopaminergic differentiation of human mesenchymal stem cells--utilization of bioassay for tyrosine hydroxylase expression. Neurosci Lett. 2007; 419: 28-33. https://doi.org/10.1016/j.neulet.2007.03.070.

32. Lu LL, Liu YJ, Yang SG, Zhao QJ, Wang X, Gong W, Han ZB, Xu ZS, Lu YX, Liu D, Chen ZZ, Han ZC. Isolation and characterization of human umbilical cord mesenchymal stem cells with hematopoiesis-supportive function and other potentials. Haematologica. 2006; 91: 1017-26. doi: 03906078 9493.

33. Seo Y, Yang SR, Jee MK, Joo EK, Roh KH, Seo MS, Han TH, Lee SY, Ryu PD, Jung JW, Seo KW, Kang SK, Kang KS. Human umbilical cord blood-derived mesenchymal stem cells protect against neuronal cell death and ameliorate motor deficits in Niemann Pick type C1 mice. Cell Transplant. 2011; 20: 1033-47. https://doi. org/10.3727/096368910X545086.

34. Gong D, Yu H, Wang W, Yang H, Han F. Human umbilical cord blood mononuclear cell transplantation for delayed encephalopathy after carbon monoxide intoxication. J Neurorestoratol. 2013; 1: 23-9.

35. Chambers SM, Fasano CA, Papapetrou EP, Tomishima M, Sadelain M, Studer L. Highly efficient neural conversion of human ES and iPS cells by dual inhibition of SMAD signaling. Nat Biotechnol. 2009; 27: 275-80. https://doi. org/10.1038/nbt. 1529.

36. Jing $\mathrm{X}$, Miwa H, Sawada $\mathrm{T}$, Nakanishi I, Kondo $\mathrm{T}$, Miyajima M, Sakaguchi K. Ephrin-A1-mediated dopaminergic neurogenesis and angiogenesis in a rat model of Parkinson's disease. PLoS One. 2012; 7: e32019. https:// doi.org/10.1371/journal.pone.0032019.

37. Hargus G, Cooper O, Deleidi M, Levy A, Lee K, Marlow E, Yow A, Soldner F, Hockemeyer D, Hallett PJ, Osborn T, Jaenisch R, Isacson O. Differentiated 
Parkinson patient-derived induced pluripotent stem cells grow in the adult rodent brain and reduce motor asymmetry in Parkinsonian rats. Proc Natl Acad Sci U S A. 2010; 107: 15921-6. https://doi.org/10.1073/ pnas. 1010209107.

38. Rhee YH, Ko JY, Chang MY, Yi SH, Kim D, Kim CH, Shim JW, Jo AY, Kim BW, Lee H, Lee SH, Suh W, Park CH, et al. Protein-based human iPS cells efficiently generate functional dopamine neurons and can treat a rat model of Parkinson disease. J Clin Invest. 2011; 121: 2326-35. https://doi.org/10.1172/JCI45794.

39. Khoo ML, Tao H, Meedeniya AC, Mackay-Sim A, Ma DD. Transplantation of neuronal-primed human bone marrow mesenchymal stem cells in hemiparkinsonian rodents. PLoS One. 2011; 6: e19025. https://doi.org/10.1371/journal. pone.0019025.

40. Blandini F, Cova L, Armentero MT, Zennaro E, Levandis G, Bossolasco P, Calzarossa C, Mellone M, Giuseppe B, Deliliers GL, Polli E, Nappi G, Silani V. Transplantation of undifferentiated human mesenchymal stem cells protects against 6-hydroxydopamine neurotoxicity in the rat. Cell Transplant. 2010; 19: 203-17. https://doi. org/10.3727/096368909x479839.

41. Ying QL, Wray J, Nichols J, Batlle-Morera L, Doble B, Woodgett J, Cohen P, Smith A. The ground state of embryonic stem cell self-renewal. Nature. 2008; 453: 51923. https://doi.org/10.1038/nature06968.

42. Xi J, Liu Y, Liu H, Chen H, Emborg ME, Zhang SC. Specification of midbrain dopamine neurons from primate pluripotent stem cells. Stem Cells. 2012; 30: 1655-63. https://doi.org/10.1002/stem.1152.

43. Doi D, Samata B, Katsukawa M, Kikuchi T, Morizane A, Ono Y, Sekiguchi K, Nakagawa M, Parmar M, Takahashi J. Isolation of human induced pluripotent stem cell-derived dopaminergic progenitors by cell sorting for successful transplantation. Stem Cell Reports. 2014; 2: 337-50. https:// doi.org/10.1016/j.stemcr.2014.01.013.

44. Vierbuchen T, Ostermeier A, Pang ZP, Kokubu Y, Sudhof TC, Wernig M. Direct conversion of fibroblasts to functional neurons by defined factors. Nature. 2010; 463: 1035-41. https://doi.org/10.1038/nature08797.

45. Pfisterer U, Kirkeby A, Torper O, Wood J, Nelander J, Dufour A, Bjorklund A, Lindvall O, Jakobsson J, Parmar M. Direct conversion of human fibroblasts to dopaminergic neurons. Proc Natl Acad Sci U S A. 2011; 108: 10343-8. https://doi.org/10.1073/pnas.1105135108.

46. Boroujeni ME, Gardaneh M. Umbilical cord: an unlimited source of cells differentiable towards dopaminergic neurons. Neural Regen Res. 2017; 12: 1186-92. https://doi. org/10.4103/1673-5374.211201.

47. Hayashi T, Wakao S, Kitada M, Ose T, Watabe H, Kuroda Y, Mitsunaga K, Matsuse D, Shigemoto T, Ito A, Ikeda H, Fukuyama H, Onoe H, et al. Autologous mesenchymal stem cell-derived dopaminergic neurons function in parkinsonian macaques. J Clin Invest. 2013; 123: 272-84. https://doi. org/10.1172/JCI62516.

48. Li JF, Yin HL, Shuboy A, Duan HF, Lou JY, Li J, Wang HW, Wang YL. Differentiation of hUC-MSC into dopaminergiclike cells after transduction with hepatocyte growth factor. Mol Cell Biochem. 2013; 381: 183-90. https://doi. org/10.1007/s11010-013-1701-z.

49. Zhang Z, Alexanian AR. Dopaminergic-like cells from epigenetically reprogrammed mesenchymal stem cells. J Cell Mol Med. 2012; 16: 2708-14. https://doi. org/10.1111/j.1582-4934.2012.01591.x.

50. Neher E. Correction for liquid junction potentials in patch clamp experiments. Methods Enzymol. 1992; 207: 123-31. doi: 0076-6879(92)07008-C.

51. Wang Y, Wang Z, Wang J, Wang Y, Henderson Z, Wang $\mathrm{X}$, Zhang X, Song J, Lu C. The modulation of nicotinic acetylcholine receptors on the neuronal network oscillations in rat hippocampal CA3 area. Sci Rep. 2015; 5: 9493. https://doi.org/10.1038/srep09493.

52. Kang X, Xu H, Teng S, Zhang X, Deng Z, Zhou L, Zuo P, Liu B, Wu Q, Wang L, Hu M, Dou H, Liu W, et al. Dopamine release from transplanted neural stem cells in Parkinsonian rat striatum in vivo. Proc Natl Acad Sci U S A. 2014; 111: 15804-9. https://doi.org/10.1073/pnas.1408484111. 